Stefan Ninković*

UDK 371.136:331.101.32

Olivera Knežević Florić

371.213:371.212.7

Filozofski fakultet

DOI: $10.19090 / \mathrm{gff} .2018 .1 .237-249$

Univerzitet u Novom Sadu

\title{
SAMOEFIKASNOST NASTAVNIKA: ISHODI, IZVORI I MERENJE KONSTRUKTA
}

Međunarodna istraživanja školskog obrazovanja ukazuju na univerzalnu relevantnost konstrukta samoefikasnosti nastavnika. Samoefikasnost nastavnika pozitivno je povezana sa efektivnim nastavnim strategijama, zadovoljstvom poslom nastavnika i akademskim postignućem učenika. Cilj ovog rada je da se predstave najvažnija saznanja o izvorima, ishodima i procesima uticaja samoefikasnosti nastavnika na važne obrazovne ishode. Uvid u rezultate dosadašnjih istraživanja omogućava razumevanja uloge samoefikasnosti nastavnika u oblikovanju kvaliteta nastave kao značajnog faktora uspešnosti svakog obrazovnog sistema. Pregled postojeće literature sugeriše da postoje određene poteškoće u merenju višedimenzionalnog konstrukta samoefikasnosti nastavnika. U zaključnom delu rada diskutuje se o implikacijama dosadašnjih saznanja o ovom konstruktu, kako za buduća istraživanja tako i za vaspitno-obrazovnu praksu.

Ključne reči: nastavnik, samoefikasnost, kvalitet nastave, kolektivna efikasnost nastavnika, socijalno-kognitivna teorija.

\section{UVOD}

Rezultati istraživanja pokazuju da kvalitet nastavnika u svakom obrazovnom sistemu predstavlja determinantu postignuća učenika (Hattie, 2009; Klassen \& Tze, 2014). Razumevanje faktora od kojih zavisi efektivnost nastavnika predstavlja prioritet ne samo brojnih istraživanja nego i obrazovnih politika na međunarodnom nivou. Samoefikasnost predstavlja jednu od ličnih karakteristika nastavnika koja se dovodi u vezu sa kvalitetom nastave i brojnim pozitivnim obrazovnim ishodima (Klassen \& Tze, 2014).

\footnotetext{
*stefan.ninkovic@ff.uns.ac.rs

${ }^{* *}$ Tekst je nastao tokom rada na projektu Značaj participacije u društvenim mrežama za prilagođavanje evrointegracijskim procesima (broj projekta 179037), finansiranom od strane Ministarstva prosvete, nauke i tehnološkog razvoja Republike Srbije.
} 
Istraživanja samoefikasnosti nastavnika su intenzivirana $\mathrm{u}$ poslednjih dvadeset godina. Međunarodne studije uspešnosti obrazovnih sistema ukazuju na univerzalnu relevantnost ovog konstrukta koji ima slične funkcije u različitim obrazovnim kontekstima (Vieluf, Kunter, \& Van de Vijver, 2013). Ovaj rad nema pretenziju da prikaže sva istraživanja u oblasti samoefikasnosti nastavnika već da narativno sumira rezultate izabranih istraživanja. Rad započinje određenjem samoefikasnosti nastavnika u okvirima socijalno-kognitivne teorije. Nakon toga dat je pregled istraživanja o izvorima i ishodima samoefikasnosti nastavnika. Pored toga, analizirana su aktuelna pitanja konceptualizovanja i merenja ovog složenog konstrukta. Posebno poglavlje rada posvećeno je ulozi kolektivne efikasnosti nastavnika.

\section{SAMOEFIKASNOST U OKVIRIMA SOCIJALNO-KOGNITIVNE TEORIJE}

Proučavajući odnos između kognicije, društvenog okruženja i ponašanja, i naglašavajući značaj ljudske proaktivnosti, Albert Bandura je razvio socijalnokognitivnu teoriju. Zahvaljujući Bandurinim radovima (1997; 2001) ova teorija utiče na istraživanja u različitim naučnim oblastima. Iako je u pedagoškim istraživanjima najčešće korišćen deo socijalno-kognitivne teorije koji govori o opservacionom učenju, i drugi njeni koncepti relevantni su za proučavanje vaspitnoobrazovnih pojava.

U diskursu socijalno-kognitivne teorije agensnost predstavlja ključni aspekt ljudskog razvoja i funkcionisanja. Bandura (1997) smatra da postoji trijadični reciprocitet između ponašanja pojedinca, karakteristika okruženja i ličnih činioca (Slika 1). Naglašavajući da se radi o ključnom konstruktu socijalno-kognitivne teorije, Bandura (1997: 3) opaženu samoefikasnost definiše kao ,procene pojedinca o sopstvenim sposobnostima organizovanja i izvršavanja akcija potrebnih za ostvarivanje željenih ciljeva". Ovo određenje implicira da osobe sa sličnim kompetencijama, ili ista osoba u različitim uslovima, može da izvede neku aktivnost različito u zavisnosti od opažene samoefikasnosti.

Socijalno-kognitivna teorija postulira da samoefikasnost može da varira u zavisnosti od konkretnog zadatka ili situacije. Nastavnici mogu da se osećaju efikasno u radu sa jednim odeljenjem a da istovremeno sebe smatraju uspešnijim ili manje efikasnim u drugačijim okolnostima. Kontekstualna uslovljenost samoefikasnosti nastavnika podrazumeva korišćenje specifičnih istraživačkih instrumenata koji omogućavaju validnu predikciju njihovog ponašanja. Primera radi, razvijene su skale procene samoefikasnosti nastavnika u oblastima nastave uz 
pomoć digitalnih tehnologija (Lemon \& Garvis, 2016) ili podučavanju učenika sa smetnjama u razvoju (Malinen et al., 2013).

Slika 1: Opšti model ljudske agensnosti (Bandura, 1997)

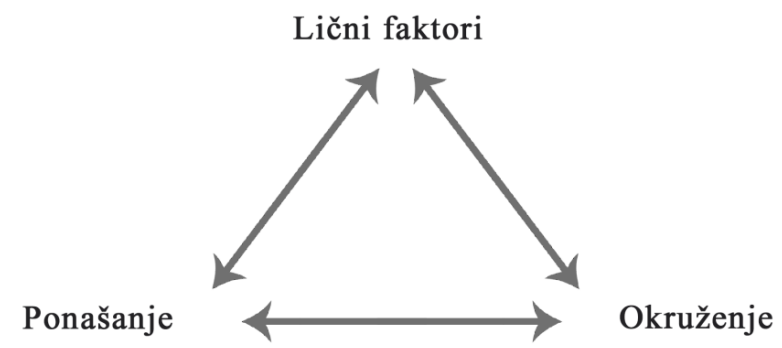

Socijalno-kognitivna teorija postulira da percepcije samoefikasnosti utiču na mišljenje, motivaciju, emocije i ponašanje pojedinca. Bandura (1997; 2001) je kao osnovne mehanizme delovanja samoefikasnosti pojedinca identifikovao kognitivne, motivacione i afektivne procese. Konkretnije rečeno, od samoefikasnosti zavisi koje ciljeve će osoba sebi postaviti, koliko će napora uložiti, koliko će biti istrajna u njihovom ostvarivanju i kako će reagovati na ostvarene ishode.

\section{IZVORI I ISHODI SAMOEFIKASNOSTI NASTAVNIKA}

Iz perspektive nastavnika opažena samoefikasnost predstavlja procenu vlastitih sposobnosti potrebnih za postizanje željenih rezultata $u$ angažovanju učenika i njihovom učenju, čak i u radu sa učenicima koji su slabo motivisani i imaju poteškoće u učenju (Tschannen-Moran \& Woolfolk Hoy, 2001). U proteklih nekoliko decenija nesumnjivo je došlo do ekspanzije istraživanja samoefikasnosti nastavnika. Klassen et al. (2011) su ustanovili da se pojam samoefikasnosti nastavnika u periodu od 1986. do 1998. godine pominje u 68 članaka objavljenih u međunarodnim časopisima, a od 1998. do 2009. godine u 218 naučnih radova. $\mathrm{Na}$ osnovu uočenih trendova izveden je zaključak da je došlo do internacionalizacije ovog istraživačkog područja $\mathrm{i}$ do značajnih pomaka $u$ razvoju metodologije ispitivanja ovog konstrukta.

Rezultati istraživanja pokazuju da je samoefikasnost nastavnika determinanta pozitivnih nastavnih ishoda. Nastavnici koji imaju razvijen osećaj samoefikasnosti obično primenjuju kompleksnije strategije podučavanja, manje su 
skloni profesionalnom sagorevanju i više su posvećeni svom poslu (Zee \& Koomen, 2016). Od samoefikasnosti zavisi u kojoj meri su nastavnici spremni da prihvate svoju ulogu u inkluzivnom obrazovanju (Malinen et al., 2013). Umerena, ali značajna, povezanost postoji između samoefikasnosti nastavnika i akademskih postignuća učenika (Klassen, Tze, Betts, \& Gordon, 2011). Međutim, Klassen et al. (2011) navode da se svega 3\% istraživanja, realizovanih u periodu 1998-2009. godine, fokusiralo na odnos samoefikasnosti nastavnika i obrazovnih postignuća učenika. Istraživači su ustanovili da između samoefikasnosti nastavnika i rezultata koje oni postižu postoji cikličan odnos (Holzberger, Philipp, \& Kunter, 2013), što je u skladu sa Bandurinom pretpostavkom o interkaciji između ponašanja pojedinca, motivacionih uverenja i faktora okruženja.

$\mathrm{Na}$ osnovu pregleda rezultata kvalitativnih i kvantitativnih istraživanja u poslednjih 40 godina Zee i Koomen (2016) zaključuju da efekti samoefikasnosti nastavnika zavise od različitih elemenata nastavnog procesa. Samoefikasnost nastavnika značajno objašnjava konstruktivistički pristup nastavi koji karakteriše kolaborativno učenje, otvorena komunikacija i povezivanje nastave sa životnim situacijama (Nie, Tan, Liau, Lau, \& Chua, 2013). Samoefikasnost nastavnika povezana je takođe sa strategijama rukovođenja u odeljenju i vaspitnim stilom nastavnika. Woolfolk i Hoy (1990) ustanovili su da nastavnici koji veruju u svoje sposobnosti nastoje da razviju samodisciplinu učenika i pritom se ređe oslanjaju na rigidna pravila ponašanja. U jednoj od studija (Guo, Piasta, Justice, \& Kaderavek, 2010) napomenuto je da nastavnici sa visokom samoefikasnošću češće kreiraju pozitivno okruženje za učenje koje karakteriše toplina, entuzijazam, podrška i efikasno korišćenje vremena. Samoefikasnost nastavnika je stabilan prediktor nivoa podrške koju nastavnici pružaju učenicima, a koja doprinosi pozitivnim odnosima između nastavnika i učenika i samim tim pozitivnoj klimi na času.

Nastavnici uverenja o svojim profesionalnim sposobnostima formiraju na osnovu iskustva (Labone, 2004; Morris, Usher, \& Chen, 2017). U procesu profesionalnog razvoja nastavnika promene uverenja i stavova obično slede nakon promena vaspitno-obrazovne prakse (Guskey, 2002). Odnos između samoefikasnosti i performansi koje nastavnik postiže je cikličan: postizanje uspeha pozitivno utiče na samoefikasnost, što posledično utiče na kvalitet nastave. Opšte pedagoško-psihološko-metodičke kompetencije nastavnika koje se odnose na planiranje nastave, strategije menadžmenta u učionici i diferenciranje nastavnih aktivnosti i zadataka takođe doprinose samoefikasnosti nastavnika (Lauermann \& König, 2016). 
Pored direktnog iskustva, značajni izvori samoefikasnosti nastavnika su vikarijsko iskustvo i verbalna persuazija. Vikarijsko iskustvo se bazira na posmatranju živih ili simboličkih modela u izvođenju određene aktivnosti. Uverenja o svojim sposobnostima nastavnici grade na osnovu posmatranja svojih mentora i kolega ili učestvujući u samomodelovanju. Na primer, posmatranje snimljenih nastavnih situacija i realizovanje nastave u virtuelnoj učionici (samomodelovanje) doprinosi samoefikasnosti nastavnika (Morris et al., 2017). Efekti ovog izvora samoefikasnosti nastavnika zavise od procene sopstvene sličnosti sa modelom.

Socijalno-kognitivna teorija implicira da će verbalna persuazija (tj. verbalno uveravanje) više uticati na samopouzdanje mlađih nastavnika kojima nedostaje autentično profesionalno iskustvo (Tschannen-Moran \& Woolfolk Hoy, 2007). Evaluativne povratne informacije koje nastavnici dobijaju iz različitih izvora mogu da utiču na njihovu samoefikasnost. Na nivou univerzitetskog obrazovanja istraživan je uticaj studentskog vrednovanja nastavnog procesa na motivaciju nastavnika. Uverenja o samoefikasnosti univerzitetskih nastavnika mogu biti delimično oblikovana povratnim informacijama studenata. Međutim, treba imati u vidu da anonimne procene studenata ne predstavljaju pouzdan pokazatelj kvaliteta nastave, budući da studenti preferiraju nastavnike koji imaju niske kriterijume (Braga, Paccagnella, \& Pellizzari, 2011). Ustanovljeno je da opažanje podrške od strane kolega, roditelja i rukovodstva škole pozitivno korelira sa samoefikasnošću nastavnika (Morris et al., 2017).

Između emocionalnih iskustava i samoefikasnosti nastavnika postoji recipročan odnos. Na primer, istraživači su pokazali da doživljaj stresa, nastao usled suočavanja sa nedisciplinovanim ponašanjem učenika, negativno utiče na samoefikasnost u domenu menadžmenta u učionici (Klassen \& Chiu, 2010). Niska samoefikasnost nastavnika može da rezultira negativnim osećanjima poput straha i stresa. S druge strane, opažena samoefikasnost nastavnika predstavlja zaštitni faktor $\mathrm{u}$ odnosu na rizik od profesionalnog sagorevanja. U tabeli 1 prikazani su osnovni izvori opažene samoefikasnosti nastavnika.

Važno pitanje odnosi se na razvoj opažene samoefikasnosti nastavnika tokom profesionalne karijere. Savremena istraživanja bazirana na složenim statističkim modelima sugerišu da se opažena samoefikasnost nastavnika postepeno povećava do 23 godine radnog staža, a da potom dolazi do njenog opadanja (Klassen \& Chiu, 2010). To znači da veza između radnog staža i samoefikasnosti nastavnika nije linearna, kao i da je samoefikasnost podložnija promenama kod nastavnika u ranim fazama karijere. Treba imati u vidu da promene u motivaciji nastavnika koje su izazvane starošću zavise od karakterstika radnog okruženja. 
Tabela 1: Izvori samoefikasnosti nastavnika (prema Morris, Usher, \& Chen, 2017)

\begin{tabular}{ll}
\hline Izvor samoefikasnosti & \multicolumn{1}{c}{ Relevantni faktori } \\
\hline Prethodno iskustvo & $\begin{array}{l}\text { autentični uspesi u radu } \\
\text { pedagoško-psihološko-metodičke kompetencije } \\
\text { stručne kompetencije }\end{array}$ \\
\hline Vikarijsko iskustvo & $\begin{array}{l}\text { posmatranje iskusnijih kolega (mentora) } \\
\text { samomodelovanje }\end{array}$ \\
\hline \multirow{2}{*}{ Socijalna persuazija } & $\begin{array}{l}\text { kredibilne i iskrene povratne informacije } \\
\text { pozitivno učeničko/studentsko vrednovanje } \\
\text { podrška od strane kolega, roditelja, školskih } \\
\text { lidera }\end{array}$ \\
\hline Emocionalna stanja & $\begin{array}{l}\text { dodeljivanje nagrada/priznanja nastavnicima } \\
\text { socijalne i emocionalne kompetencije nastavnika }\end{array}$ \\
\hline
\end{tabular}

U vezi sa prethodnim pitanjem, istraživači su ispitivali doprinose pojedinih faktora samoefikasnosti nastavnika u različitim fazama profesionalne karijere. U tom smislu, nivo doprinosa pojedinih prediktora samoefikasnosti nastavnika zavisi od načina merenja konstrukta (Woolfolk Hoy \& Spero, 2005). Postoje saznanja da kontekstualni faktori, kao što su stil obrazovnog liderstva direktora škole i školska klima, imaju veći uticaj na samoefikasnost mlađih nastavnika (Tschannen-Moran \& Hoy, 2007). Ovi uvidi se tumače pretpostavkom da je iskusnijim nastavnicima u većoj meri dostupno autentično profesionalno iskustvo koje njihove samoprocene čini manje podložnim spoljašnjim faktorima.

\section{KONCEPTUALIZOVANJE I MERENJE SAMOEFIKASNOSTI NASTAVNIKA}

Iako se istraživači slažu da samoefikasnost nastavnika predstavlja prediktor značajnih pozitivnih nastavnih ishoda, postoje neslaganja po pitanju definisanja i merenja konstrukta. Prema nekim uvidima, u jednoj trećini studija samoefikasnosti nastavnika, realizovanih u periodu 1998-2009. godine, korišćeni su konceptualno problematični instrumenti (Klassen et al., 2011). Najveća slabost ovih mera odnosi se na neuvažavanje implikacija Bandurine socijalno-kognitivne teorije. Takođe, neki od instrumenata bazirani su na pogrešnom određenju samoefikasnosti nastavnika kao jednodimenzionalnog konstrukta (Skaalvik \& Skaalvik, 2007; Wyatt, 2014).

Takva situacija rezultirala je razvojem alternativnih instrumenta za ispitivanje samoefikasnosti nastavnika. Megan Tschannen Moran i Anita Woolfolk Hoy (2001) su, uvažavajući Bandurine preporuke, kreirale Skalu samoefikasnosti nastavnika (TSES; The Teachers' Sense of Efficacy Scale) koja predstavlja 
najčešće korišćeni instrument $u$ ovoj oblasti. Ova skala je bazirana na shvatanju nastavničke profesije kao kompleksne delatnosti koja obuhvata više relevantnih aspekata. Kratka (12 stavki) i duga (24 stavki) verzija instrumenta ispituju tri međusobno povezana faktora koji reflektuju tri oblasti podučavanja: instrukcija, upravljanje odeljenjem i angažovanje učenika. Zbog dobrih metrijskih karakteristika koje su potvređene u različitim zemljama (Klassen et al., 2009), ovaj instrument se smatra superirornim u odnosu na prethodno korišćene. Zanimljivo je istaći da istraživanja na uzorcima studenata nastavničkih fakulteta ukazuju na jednodimenzionalnost strukture ove skale (Duffin, French, \& Patrick, 2012). Pretpostavlja se da budući nastavnici, usled ograničenosti sopstvenog pedagoškog iskustva, ne prave razliku između različitih aspekata nastavnog rada.

Neki istraživači smatraju da ulogu nastavnika nije moguće redukovati na tri dimenzije i predlažu diferenciranje konstrukta na veći broj komponenti. Strukturu Norveške skale samoefikasnosti nastavnika (Skaalvik \& Skaalvik, 2007) čini šest dimenzija: instrukcija, individualizovanje nastave, motivisanje učenika, održavanje reda i discipline, saradnja sa kolegama i roditeljima i suočavanje sa promenama i izazovima. Autori smatraju da šest izdvojenih dimenzija reflektuju bazične profesionalne kompetencije nastavnika.

Polazeći od uticaja vršnjačkih odnosa na akademska postignuća i socijalno ponašanje učenika, Ryan, Kuusinen i Bedoya-Skoog (2015) uveli su novu dimenziju samoefikasnosti nastavnika koja se odnosi na upravljanje vršnjačkim odnosima. Autori ovu dimenziju povezuju sa nastavničkim samoprocenama sposobnosti potrebnih za kreiranje razredne klime koju karakterišu pozitivni socijalni odnosi između učenika. Važno je istaći da su uočene razlike u prisustvu samoefikasnosti u upravljanju vršnjačkim odnosima između nastavnika u osnovnoj i srednjoj školi. To je moguće protumačiti činjenicom da sa ulaskom u adolescenciju vršnjački odnosi postaju složeniji i da razvojne promene nastavnicima otežavaju upravljanje ponašanjem učenika i odnosima među vršnjacima.

Dosadašnja istraživanja samoefikasnosti nastavnika dominantno su kvantitativnog karaktera, dok je intepretativna paradigma gotovo potpuno odsutna. Neki od istraživača (Wyatt, 2014) dovode u pitanje pouzdanost samoprocene nastavnika, ukazujući na probleme naivnog optimizma i socijalno poželjnih odgovora. U tom smislu, postoji potreba za kvalitativnim i kombinovanim studijama koje bi bile bazirane na triangulaciji različitih izvora podataka. Pored toga, kvantitativna istraživanja suočena su sa značajnim pitanjem koje se odnosi na stepen situacione uslovljenosti samoefikasnosti nastavnika. Iz tog razloga postoje instrumenti koji mogu da se koriste $\mathrm{u}$ ispitivanju samoefikasnosti nastavnika svih 
predmeta na svim nivoima obrazovanja, ali i instrumenti dizajnirani za nastavnike posebnih grupa predmeta (npr. prirodne nauke).

\section{ULOGA KOLEKTIVNE EFIKASNOSTI NASTAVNIKA}

Međunarodna istraživanja nastave i učenja pokazuju da saradnja nastavnika značajno doprinosi zadovoljstvu poslom nastavnika, njihovoj samoefikasnosti i korišćenju inovativnih strategija podučavanja. Uspešne školske sisteme (npr. Finska) karakteriše profesionalna saradnja nastavnika koja doprinosi kontinuiranom unapređenju nastave i postignuća učenika (OECD, 2013). Uticaj horizontalnih mreža nastavnika na obrazovna postignuća učenika posredovan je efikasnošću kolektiva (Moolenaar, Sleegers, \& Daly, 2012).

Kolektivna efikasnost nastavnika predstavlja ,procenu nastavnika da kolektiv u celini može da organizuje i izvrši određene akcije koje će pozitivno uticati na učenike" (Goddard, Hoy, \& Hoy, 2004: 4). Analogno delovanju opažene samoefikasnosti, kolektivna efikasnost nastavnika utiče na izbor ciljeva koje školski kolektiv želi da ostvari, izbor strategija delovanja, stepen ulaganja napora i istrajnost u postizanju željenih ishoda uprkos teškoćama. Goddard, Hoy i Hoy (2000) ustanovili su da kolektivna efikasnost nastavnika predstavlja značajan faktor postignuća učenika, čak i nakon kontrolisanja doprinosa prethodnog postignuća i socio-ekonomskog statusa učenika. Longitudinalno je potvrđena povezanost problema u ponašanju učenika i kolektivne efikasnosti nastavnika (Sørlie \& Torsheim, 2011). Na osnovu rezultata prethodnih istraživanja evidentno je da je kolektivna efikasnost nastavnika povezana kako sa akademskim razvojem tako i sa socijalnim ponašanje učenika.

Prema mišljenju nekih istraživača (Goddard et al., 2004; Skaalvik \& Skaalvik, 2007), kolektivna efikasnost nastavnika predstavlja jedan od aspekata školskog okruženja koji utiče na individualne percepcije i ponašanje nastavnika. Pretpostavlja se da proces socijalne identifikacije rezultira zasnivanjem individualnog ponašanja na kolektivnim normama, očekivanjima i vrednostima referentne grupe. S druge strane, istraživanja ovog odnosa (Ninković \& Knežević Florić, 2018) pokazuju da samoefikasnost nastavnika predstavlja nezavisan prediktor njihovog uverenja o kolektivnoj efikasnosti. Ujednačene procene samoefikasnosti nastavnika u istom kolektivu olakšavaju međusobno usaglašavanje o zajedničkim prioritetima i načinima njihovog ostvarivanja. Ovi nalazi su u skladu sa pretpostavkom socijalno-kognitivne teorije o međuodnosu dva oblika efikasnosti nastavnika - individualne i kolektivne. Relacije samoefikasnosti i kolektivne 
efikasnosti nastavnika mogu biti interpretirane u kontekstu recipročne uslovljenosti kontekstualnih činilaca i samoefikasnosti nastavnika.

Socijalno-kognitivna teorija postulira da opažena lična i kolektivna efikasnost imaju slične izvore i funkcije. Istraživači nastoje da potpunije razumeju načine podsticanja kolektivne efikasnosti nastavnika. Jedan od faktora koji se pokazao kao stabilna odrednica kolektive efikasnosti nastavnika jeste liderstvo u školskom okruženju. Naime, potvrđena je pretpostavka da transformacioni stil vođenja od strane direktora škole značajno doprinosi opaženoj kolektivnoj efikasnosti nastavnika (Ninković \& Knežević Florić, 2018). S obzirom da kolektivna efikasnost zavisi od nivoa interpersonalne interakcije članova grupe, školskim liderima se predlaže da rade na podsticanju horizontalnog umrežavanja i timskog rada nastavnika. Razmenjivanjem znanja, deljenjem iskustava i zajedničkim traganjem za rešenjima problema nastavnici mogu da grade poverenje u kapacitete kolektiva kojem pripadaju.

\section{ZAKLJUČAK}

$\mathrm{Na}$ osnovu pregleda naučne literature može se zaključiti da je samoefikasnost nastavnika determinanta važnih obrazovnih ishoda. Prethodna istraživanja bila su fokusirana na povezanost samoefikasnosti nastavnika sa njihovim ličnim karakteristikama, kao što su nivo zadovoljstva poslom ili profesionalnog sagorevanja. Međutim, primetno je da istraživači nisu dovoljno pažnje posvetili doprinosu samoefikasnosti nastavnika školskom uspehu učenika. Iako su identifikovani važni prediktori samoefikasnosti nastavnika, neophodno je istražiti da li se i na koji način njihovi efekti menjaju tokom profesionalne karijere nastavnika. Osim toga, u budućim istraživanjima potrebno je longitudinalno proučavati međuodnos samoefikasnosti nastavnika, s jedne, i kvaliteta podučavanja i učenja, s druge strane. Nalazi dosadašnjih istraživanja sugerišu da potpunije razumevanje uticaja opažene lične i kolektivne efikasnosti nastavnika podrazumeva pragmatično kombinovanje kvalitativnih i kvantitatnih istraživačkih pristupa.

Motivaciona uverenja čine jedan od osnovnih elemenata profesionalnih kompetencija nastavnika. Istraživanja karakteristika motivacije nastavnika mogu da pruže značajne implikacije za unapređenje kvaliteta nastavnog procesa. Budući da obeležja društveno-kulturnog okruženja utiču na sistem obrazovanja, istraživanja samoefikasnosti nastavnika u Srbiji su potrebna i mogla bi da doprinesu kvalitetnijoj selekcije nastavnika, razvoju njihovog incijalnog i profesionalnog obrazovanja, kao i unapređenju vaspitno-obrazovne prakse. 
Stefan Ninković, Olivera Knežević Florić

TEACHER SELF-EFFICACY: OUTCOMES, SOURCES AND CONSTRUCT MEASUREMENT

\section{Summary}

In the past twenty years, social cognitive theory has received a great deal of attention from educational researchers. This theory postulates that teacher self-efficacy affects a number of important outcomes for both teachers and students. International education assessments indicate a universal relevance of this construct, regardless of differences in national contexts. The results of previous studies have shown that teacher self-efficacy is a predictor of numerous desired outcomes, including student achievement, teacher job satisfaction and commitment.

An insight into the results of existing research enables understanding of the role of teacher self-efficacy in the shaping of the quality of teaching, which is a significant factor in the success of every educational system. The aim of this paper is to present the most significant ideas about the sources and outcomes of teacher self-efficacy and classroom processes that mediate the relationships between this construct and important educational outcomes. The most important sources of teachers' self-efficacy are mastery experiences, vicarious experiences, verbal persuasion, and emotional states. The effects of teacher self-efficacy are mediated by different classroom processes, such as instructional support, effective classroom management, and emotional teacher support. It is evident that the researchers have agreed that teacher self-efficacy is a multidimensional construct whose examination involves the application of assessment tools that take into account the domain specificity of the teachers' beliefs about their own capabilities necessary to achieve the desired outcomes. Despite this fact, there are still some conceptual difficulties in measuring this construct. Social cognitive theory supports the idea of a reciprocal relationship between two forms of teachers' efficacy: individual and collective. In the final part of the paper, it is concluded that the research of teacher self-efficacy in Serbia would not only enable a comparison of the results with foreign studies, but also have significant practical implications.

Key words: teacher, self-efficacy, quality of instruction, collective teacher efficacy, social cognitive theory

\section{LITERATURA}

Bandura, A. (1997). Self-efficacy: The exercise of control. New York, NJ: Freeman Lawrence.

Bandura, A. (2001). Social cognitive theory: An agentic perspective. Annual Review of Psychology, 52(1), 1-26. https://doi.org/10.1146/annurev. psych.52.1.1 
Braga, M., Paccagnella, M., \& Pellizzari, M. (2011). Evaluating students ' evaluations of professors. Economics of Education Review, 41(September 2010), 71-88.

Duffin, L. C., French, B. F., \& Patrick, H. (2012). The Teachers' Sense of Efficacy Scale: Confirming the factor structure with beginning pre-service teachers. Teaching and Teacher Education, 28(6), 827-834. https://doi.org/10.1016/ j.tate.2012.03.004

Goddard, R. D., Hoy, W. K., \& Hoy, A. W. (2000). Collective teacher efficacy: Its meaning, measure, and impact on student achievement. American Educational Research Journal, 37(2), 479-507. https://doi.org/10.3102/ 00028312037002479

Goddard, R., Hoy, W., \& Hoy, A. (2004). Collective efficacy beliefs: Theoretical development, empirical evidence, and future directions. Educational Research, 33(3), 3-13. https://doi.org/10.3102/0013189X033003003

Guo, Y., Piasta, S. B., Justice, L. M., \& Kaderavek, J. N. (2010). Relations among preschool teachers' self-efficacy, classroom quality, and children's language and literacy gains. Teaching and Teacher Education, 26(4), 1094-1103. https://doi.org/10.1016/j.tate.2009.11.005

Guskey, T. R. (2002). Professional development and teacher change. Teachers and Teaching: Theory and Practice, 8(3), 381-391. https://doi.org/10.1080/ 135406002100000512

Hattie, J. (2009). Visible learning: A synthesis of over 800 meta-analyses relating to achievement. London: Routledge.

Holzberger, D., Philipp, A., \& Kunter, M. (2013). How teachers' self-efficacy is related to instructional quality: A longitudinal analysis. Journal of Educational Psychology, 105(3), 774-786. https://doi.org/10.1037/ a0032198

Klassen, R. M., Bong, M., Usher, E. L., Chong, W. H., Huan, V. S., Wong, I. Y. F., \& Georgiou, T. (2009). Exploring the validity of a teachers' self-efficacy scale in five countries. Contemporary Educational Psychology, 34(1), 67-76. https://doi.org/10.1016/j.cedpsych.2008.08.001

Klassen, R. M., \& Chiu, M. M. (2010). Effects on teachers' self-efficacy and job satisfaction: Teacher gender, years of experience, and job stress. Journal of Educational Psychology, 102(3), 741-756. https://doi.org/10.1037/ a0019237

Klassen, R. M., \& Tze, V. M. C. (2014). Teachers' self-efficacy, personality, and teaching effectiveness: A meta-analysis. Educational Research Review, 12, 59-76. https://doi.org/10.1016/j.edurev.2014.06.001

Klassen, R. M., Tze, V. M. C., Betts, S. M., \& Gordon, K. A. (2011). Teacher efficacy research 1998-2009: Signs of progress or unfulfilled promise? 
Educational Psychology Review, 23(1), 21-43. https://doi.org/10.1007/ s10648-010-9141-8

Labone, E. (2004). Teacher efficacy: Maturing the construct through research in alternative paradigms. Teaching and Teacher Education, 20(4), 341-359. https://doi.org/10.1016/j.tate.2004.02.013

Lauermann, F., \& König, J. (2016). Teachers' professional competence and wellbeing: Understanding the links between general pedagogical knowledge, self-efficacy and burnout. Learning and Instruction, 45, 9-19. https://doi.org/10.1016/j.learninstruc.2016.06.006

Lemon, N., \& Garvis, S. (2016). Pre-service teacher self-efficacy in digital technology. Teachers and Teaching: Theory and Practice, 22(3), 387-408. https://doi.org/10.1080/13540602.2015.1058594

Malinen, O., Savolainen, H., Engelbrecht, P., Xu, J., Nel, M., \& Nel, N. (2013). Exploring teacher self-efficacy for inclusive practices in three diverse countries. Teaching and Teacher Education, 33, 34-44.

Moolenaar, N. M., Sleegers, P. J. C., \& Daly, A. J. (2012). Teaming up: Linking collaboration networks, collective efficacy, and student achievement. Teaching and Teacher Education, 28(2), 251-262. https://doi.org/10.1016/ j.tate.2011.10.001

Morris, D. B., Usher, E. L., \& Chen, J. A. (2017). Reconceptualizing the sources of teaching self-efficacy: a critical review of emerging literature. Educational Psychology Review, 29(4), 795-833. 10.1007/s10648-016-9378-y

Nie, Y., Tan, G. H., Liau, A. K., Lau, S., \& Chua, B. L. (2013). The roles of teacher efficacy in instructional innovation: Its predictive relations to constructivist and didactic instruction. Educational Research for Policy and Practice, 12(1), 67-77. https://doi.org/10.1007/s10671-012-9128-y

Ninković, S. R., \& Knežević Florić, O. (2018). Transformational school leadership and teacher self-efficacy as predictors of perceived collective teacher efficacy. Educational Management Administration and Leadership, 46(1), 49-64. https://doi.org/10.1177/1741143216665842

OECD (2013). Teaching and Learning International Survey (TALIS 2013): Conceptual framework. Paris: OECD Publishing. Preuzeto sa http://www.oecd.org/education/school/TALIS\%20Conceptual\%20Framewor k_FINAL.pdf

Ryan, A. M., Kuusinen, C. M., \& Bedoya-Skoog, A. (2015). Managing peer relations: A dimension of teacher self-efficacy that varies between elementary and middle school teachers and is associated with observed classroom quality. 
Contemporary Educational Psychology, 41, 147-156. https://doi.org/ 10.1016/j.cedpsych.2015.01.002

Skaalvik, E. M., \& Skaalvik, S. (2007). Dimensions of teacher self-efficacy and relations with strain factors, perceived collective teacher efficacy, and teacher burnout. Journal of Educational Psychology, 99(3), 611-625. https://doi.org/10.1037/0022-0663.99.3.611

Sørlie, M.-A., \& Torsheim, T. (2011). Multilevel analysis of the relationship between teacher collective efficacy and problem behaviour in school. School Effectiveness and School Improvement, 22(2), 175-191. https://doi.org/ 10.1080/09243453.2011.563074

Tschannen-Moran, M., \& Hoy, A. W. (2007). The differential antecedents of selfefficacy beliefs of novice and experienced teachers. Teaching and Teacher Education, 23(6), 944-956. https://doi.org/10.1016/j.tate.2006.05.003

Tschannen-Moran, M., \& Woolfolk Hoy, A. (2001). Teacher efficacy: Capturing an elusive construct. Teaching and Teacher Education, 17(7), 783-805. https://doi.org/10.1016/S0742-051X(01)00036-1

Vieluf, S., Kunter, M., \& Van de Vijver, F. J. R. (2013). Teacher self-efficacy in cross-national perspective. Teaching and Teacher Education, 35, 92-103. https://doi.org/10.1016/j.tate.2013.05.006

Woolfolk, A. E., \& Hoy, W. K. (1990). Prospective teachers' sense of efficacy and beliefs about control. Journal of Educational Psychology, 82(1), 81-91. https://doi.org/10.1037/0022-0663.82.1.81

Woolfolk Hoy, A., \& Spero, R. B. (2005). Changes in teacher efficacy during the early years of teaching: A comparison of four measures. Teaching and Teacher Education, 21(4), 343-356. https://doi.org/10.1016/j.tate. 2005.01.007

Wyatt, M. (2014). Towards a re-conceptualization of teachers' self-efficacy beliefs: Tackling enduring problems with the quantitative research and moving on. International Journal of Research \& Method in Education, 37(2), 166-189. https://doi.org/10.1080/1743727X.2012.742050

Zee, M., \& Koomen, H. M. Y. (2016). Teacher self-efficacy and its effects on classroom processes, student academic adjustment, and teacher well-being: A synthesis of 40 years of research. Review of Educational Research, 86(4), 981-1015. https://doi.org/10.3102/0034654315626801 